\title{
LA IMPLEMENTACIÓN DEL ACUERDO DE PAZ EN COLOMBIA: ENTRE LA “PAZ TERRITORIAL” Y LA DISPUTA POR EL TERRITORIO
}

\begin{abstract}
Consuelo Ahumada ${ }^{a}$
Fecha de recepción: 20 de mayo de 2019. Fecha de aceptación: 16 de octubre de 2019.

https://doi.org/10.22201/iiec.20078951e.2020.200.69502

Resumen. La firma del Acuerdo Final entre el Gobierno Nacional y las Fuerzas Armadas Revolucionarias de Colombia (FARC), el 24 de noviembre de 2016, generó muchas expectativas. Sin embargo, los importantes avances alcanzados durante los meses subsecuentes dieron paso a un periodo de estancamiento e incluso de franco retroceso en su implementación. En este artículo se analizarán las dificultades en el cumplimiento del Acuerdo Final, en especial, en lo que respecta a su primer punto sobre Reforma Rural Integral (RRI). El análisis parte del planteamiento de que, si bien este Acuerdo se centró en generar las condiciones para culminar con el conflicto armado y el restablecimiento de las condiciones democráticas en el país, también se tienen factores estructurales que atentan contra la consolidación de la paz.
\end{abstract}

Palabras clave: Acuerdo de paz; conflicto armado; disputa por la tierra; neoliberalismo; FARC.

Clasificación JEL: D74; F59; N36; O18.

\section{Implementing the Peace Agreement in Colombia: BETWEEN “TERRITORIAL PEACE” AND LAND DISPUTES}

\begin{abstract}
The signing of the Final Agreement between the Colombian National Government and the Revolutionary Armed Forces of Colombia (FARC) on November 24, 2016, created many expectations. However, key advances that were achieved during the subsequent months gave way to a period of stagnation and even actual backsliding in its implementation. This paper analyzes the difficulties of fulfilling the Final Agreement, in particular as concerns its first point regarding Comprehensive Rural Reform (CRR). The analysis is based on the argument that if the Agreement was focused on generating the conditions necessary to end armed conflict and reestablish democratic conditions in the country, it also contains structural factors which infringe upon the consolidation of peace.
\end{abstract}

Key Words: Peace Agreement; armed conflict; land disputes; neoliberalism; FARC.

${ }^{a}$ Facultad de Ciencias Sociales y Humanas, Centro de Estudios de Dinámica Social, Universidad Externado de Colombia, Colombia. Correo electrónico: cahumadabg@gmail.com 


\section{INTRODUCCIÓN}

En medio de una fuerte polarización política que ha marcado las últimas décadas de la historia de Colombia, la firma definitiva del Acuerdo Final para la terminación del conflicto y la construcción de una paz estable y duradera (AF, 2016), entre el Gobierno Nacional y las Fuerzas Armadas Revolucionarias de Colombia (FARC), el 24 de noviembre de 2016, generó toda suerte de expectativas en el país, la región y el mundo entero. ${ }^{1}$ Sin embargo, los importantes avances alcanzados durante los meses posteriores, sobre todo en los planos político y jurídico, dieron paso a un periodo de estancamiento e incluso de franco retroceso en su implementación.

A manera de contexto, es necesario tener en cuenta la confluencia de factores interrelacionados que determinaron las condiciones por las que ha transitado Colombia. El primero de ellos es la persistencia, intensificación y degradación de un conflicto armado que se prolongó por más de medio siglo. ${ }^{2}$ El segundo factor es el abandono histórico o la presencia precaria del Estado en importantes regiones del país y el fracaso de las élites en la construcción de un modelo de desarrollo que las integre, reconozca y preserve en su diversidad, al tiempo que procure a sus habitantes mejores condiciones de vida. El tercero es respecto a la imposición de políticas excluyentes, derivadas de la globalización neoliberal de los años noventa del siglo xx, mismas que fueron acogidas de manera entusiasta y sin cuestionamiento por todos los gobiernos de América Latina.

Dichas medidas fueron la reducción de la función económica y social del Estado y de sus instituciones, en especial en el sector rural; el menosprecio de la producción nacional y del mercado interno, para beneficiar a grandes negocios extranjeros y nacionales, así como las políticas de ajuste fiscal y restricción del gasto público, entre otras. Adicionalmente, desde mediados de la

El AF incluye los siguientes puntos: 1) Reforma Rural Integral (RRI); 2) Participación política; 3) Fin del conflicto; 4) Solución al problema de las drogas ilícitas; 5) Víctimas y sistema integral de verdad, justicia, reparación y no repetición, y 6) Mecanismos de implementación, refrendación y verificación (AF, 2016).

2 Desde mediados de la década de los cuarenta del siglo pasado, Colombia vivió el periodo conocido como "La Violencia”, que concluyó en 1958 con la conformación del Frente Nacional, un pacto entre las élites de los dos partidos tradicionales (el Liberal y el Conservador). Este cruento conflicto, presentado como una confrontación bipartidista, trajo una mayor concentración de la tierra en manos de los terratenientes, así como el despojo y la migración forzada de aproximadamente 2 millones de personas y un saldo de más de 300 mil muertos. Sin embargo, el conflicto armado más reciente y prolongado dio inicio en 1964, bajo el contexto de la Guerra Fría, cuando se conformaron las FARC y el Ejército de Liberación Nacional (ELN). 
década de los ochenta, la disputa por el control territorial para la producción y comercialización de la droga derivada de la coca y para otros negocios ilícitos irrumpe en el conflicto armado colombiano como un acelerador de partículas, generando una máquina de destrucción. Los anteriores factores tuvieron un impacto decisivo en la crisis del sector rural y en la prolongación del conflicto armado en el país.

Fue durante el proceso de negociación y refrendación del AF que terminó por aceptarse que su objetivo central era restablecer las condiciones democráticas mínimas que permitieran resolver los conflictos de manera pacífica, propiciar la movilización política y social amplia y competir por el poder del Estado sin el recurso de las armas, pero sí con las garantías legales. Es decir, la finalización del conflicto armado permitiría despejar el camino para que el Estado y la sociedad pudieran concentrarse en atender y resolver los asuntos cruciales del postergado desarrollo económico y social. Ese fue el sentido de la negociación. Por fuera de la discusión quedó el cambio del modelo de desarrollo y de las políticas derivadas del mismo.

En el presente artículo se analizarán las perspectivas y dificultades del cumplimiento del AF, en lo que respecta al primer punto. Se parte pues del planteamiento de que, si bien es cierto que este Acuerdo se centró en generar las condiciones para la finalización del conflicto armado, la reincorporación de los excombatientes a la vida civil y política, así como la democratización del país, hay factores estructurales serios que dificultaron la consolidación de una "paz estable y duradera" como: 1) la continua disputa por el dominio territorial; 2) el control del Estado por parte de los enemigos del AF; y 3) el modelo de desarrollo predominante, en Colombia y en el mundo.

El análisis se estructura en cuatro secciones: la primera, esta introducción, en la segunda se examinan algunos de los principales enfoques teóricos sobre la relación entre instituciones, paz y desarrollo y su expresión en el concepto de "paz territorial". En la tercera sección, se analizan la disputa territorial y la polarización política en torno al AF; la cuarta se centra en las principales dificultades del punto sobre la RRI, en el nuevo contexto nacional. Por último, se plantean algunas conclusiones. 


\section{DISCUSIÓN TEÓRICA: RELACIÓN ENTRE PAZ, INSTITUCIONES Y DESARROLLO}

\section{Las instituciones y el desarrollo}

Durante los últimos años, la implementación del Acuerdo de paz convirtió en prioritario un debate que venía dándose de tiempo atrás. En el campo de la economía política y los estudios del desarrollo, la relación entre el afianzamiento de la paz y las perspectivas del desarrollo económico y social fue abordada desde varios enfoques. Para empezar, debe tenerse en cuenta que las reformas resultantes del Consenso de Washington de 1989, conocidas como de primera generación, dieron paso hacia finales del siglo a las reformas institucionales llamadas de segunda generación. Mediante ellas se pretendía reorientar el debilitado papel asignado inicialmente al Estado, con la premisa de que la deficiencia de las instituciones había provocado el fracaso de las primeras reformas. Las autoridades económicas internacionales encontraron así los argumentos teóricos y políticos para proporcionarles legitimidad a las medidas y adjudicarles a los gobiernos la responsabilidad principal por sus consecuencias, desconociendo las presiones internacionales (Banco Mundial, 1997)..$^{3}$

La corriente de pensamiento económico que en las dos últimas décadas ha orientado las decisiones de los organismos financieros es el neoinstitucionalismo. Aunque el término incluye una diversidad de matices, este enfoque tiene como referente principal al premio Nobel de Economía, el estadounidense Douglass North quien definió las instituciones como "toda forma de restricción que los seres humanos crean para dar forma a la interacción humana" y cuya principal función es "reducir la incertidumbre" (North, 1993, pp. 2-3). De acuerdo con esta concepción, las instituciones, formales e informales, entendidas como las reglas de juego de una sociedad, son fundamentales para explicar su comportamiento y el cambio económico; y deben garantizar el funcionamiento adecuado del sistema capitalista y la protección de los derechos de propiedad. Debe contarse también con un sistema de justicia imparcial y eficiente que garantice la resolución de los conflictos (Kalmanovitz, 2003).

Desde finales del siglo pasado, la visión neoinstitucionalista se impuso también en el ámbito más amplio de las ciencias sociales, con la noción de

3 Para una visión más detallada de este enfoque, véase Kuczynski y Williamson (2003). 
que el papel principal en el desarrollo nacional lo tienen las instituciones y el cambio organizacional, más no la acumulación de capital, como lo plantearon los teóricos del desarrollo. Al respecto, Portes analiza cómo la sociología del desarrollo dio también un "giro institucional" y se forjó un nuevo consenso expresado en "el intento de exportar códigos legales y planos organizativos a los países del sur, de manera uniforme y sin matices". El cuestionamiento que él hace de lo que en esa disciplina se conoce como nuevo institucionalismo, se origina en su olvido de una rica herencia teórica, sin proponer alternativas, sino más bien recurriendo a nociones imprecisas. Un punto clave es el desconocimiento de las relaciones de poder en el moldeamiento de dichas instituciones, así como del concepto y la existencia de las clases sociales: "El resultado práctico más tangible del advenimiento del institucionalismo en el campo del desarrollo económico es el intento de trasplantar las formas institucionales del Occidente desarrollado, especialmente de Estados Unidos, al mundo menos desarrollado" (Portes, 2006). ${ }^{4}$

El enfoque neoinstitucionalista predominante en las esferas del poder económico global elude también las relaciones de poder, así como la valoración histórica precisa sobre el papel del Estado y las instituciones. En términos prácticos, no difiere de los preceptos ni de las presunciones neoliberales que guiaron las reformas de los ochenta y noventa. Sus recetas son generales y abstractas y no consultan para nada las condiciones económicas y sociales específicas de países, regiones y territorios. Aunado a ello, insiste en despojar al Estado de su función en el desarrollo, que históricamente cumplió en el capitalismo (Vilas, 2000). Eso sí, lo responsabiliza de los resultados de las políticas impuestas.

En consonancia con este enfoque, prevalece una visión burocrática y tecnocrática que, en aras del predominio del mercado, pretende desconocer las diferencias regionales y la ausencia o debilidad histórica del Estado en amplios sectores del territorio nacional. En Colombia algunas de estas regiones fueron de las más afectadas por el conflicto armado. Así, se da prioridad a los instrumentos de gestión, provenientes del sector privado, al tiempo que se pretende reducir la política a la administración (Vilas, 2000; López, 2005).

4 En este punto, Portes retoma lo que Peter Evans, otro de los sociólogos del desarrollo, denominó "monocultivo institucional", caracterizándolo como el intento de trasplantar instituciones construidas durante varios siglos en los países desarrollados, a países diferentes, esperando obtener resultados similares (Portes, 2006, p. 26). Contrario a esta tendencia, valdría la pena destacar el aporte de la sociología histórica, desarrollado por Moore (1991), quien estudia el papel del Estado y las instituciones en el desarrollo de los países, a partir de su historia y condiciones específicas. 
Para abordar el análisis de la relación entre instituciones y desarrollo resulta conveniente hacer referencia al llamado neokeynesianismo. Quienes abogan por este enfoque han cuestionado algunas de las políticas trazadas por los organismos internacionales frente a la crisis económica global, en especial, las que le apuntan a reducir el déficit fiscal y a imponer medidas de austeridad. Aunque en términos generales comparten la visión neoinstitucionalista predominante, cuestionan los excesos del llamado libre mercado, el incremento de la desigualdad y de la concentración de la riqueza en el mundo y claman por un papel más determinante por parte del Estado para frenar dicha tendencia. ${ }^{5}$

Es a partir de este mismo enfoque de corte socialdemócrata, pero con una postura más crítica del orden global, que habría que hacer referencia también a algunos de los trabajos publicados por OXFAM Internacional. En su informe de 2019, documenta de manera extensa el proceso de concentración de la riqueza en el mundo, en particular durante la última década. Sus recomendaciones, tendientes a reducir las dos grandes brechas de la desigualdad entre ricos y pobres y entre hombres y mujeres, incluyen la universalización de la provisión gratuita de servicios públicos como la salud y la educación y la reversión de la tendencia a reducir la tributación a los sectores más ricos (OXFAm, 2019).

En el plano de la práctica política, la experiencia de los llamados gobiernos alternativos de América del Sur durante la primera parte de este siglo y su confrontación con el orden económico vigente es bastante ilustrativa. Aunque el alcance de sus políticas y el balance de sus resultados, aciertos y desaciertos, varían de país a país, todos estos gobiernos comparten la preocupación por mejorar las condiciones de vida de la población. Reivindican la función del Estado y la inversión pública y social sostenida, así como la lucha contra la pobreza, mediante el incremento de los recursos fiscales provenientes de los impuestos a la explotación de los hidrocarburos y la minería. A la par, impulsan procesos políticos participativos, que permiten visibilizar a sectores sociales que históricamente estuvieron marginados. Estos gobiernos defienden el concepto de soberanía nacional, el manejo y control del territorio y de los recursos naturales por parte del Estado y la Nación, al tiempo que intentan subordinar la inversión extranjera al interés prioritario del fortalecimiento del mercado interno y del desarrollo nacional. Sin duda, la implementación a

5 El término neokeynesianismo, introducido por Paul Samuelson, planteaba en un inicio integrar algunos principios de la economía neoclásica con el keynesianismo. Joseph Stiglitz y Paul Krugman son los principales exponentes de esta tendencia. 
fondo del AF y el rescate de los territorios más golpeados por el conflicto armado en Colombia requieren de la puesta en práctica de un enfoque basado en lineamientos semejantes.

Sin embargo, en el mundo siguen predominando las políticas de ajuste fiscal que restringen la inversión pública y social y favorecen la concentración de la riqueza, mientras que cualquier otra opción es descalificada de plano y condenada. Este es uno de los componentes del entorno internacional que resulta adverso para la implementación del AF en Colombia. El otro es el auge a nivel global de la agenda de la extrema derecha, representada por el presidente Donald Trump, que privilegia, entre otras tendencias, al incremento en el gasto militar y la guerra, y menosprecia la salida negociada a los conflictos.

\section{El concepto de "paz territorial"}

Aunque los defensores del AF coinciden en la necesidad de su implementación plena e inmediata, plantean interpretaciones diversas en cuanto a su alcance, que se desprenden de algunos de los enfoques arriba analizados. De acuerdo con la visión que prevalece, la consolidación de la paz en un determinado territorio o país es un requisito para afianzar la economía de mercado e incrementar la inversión privada, nacional y extranjera. Se trata ante todo de facilitar las condiciones óptimas para la extracción de recursos naturales, en especial del sector minero energético, y para el desarrollo de la agricultura de exportación a gran escala. Fue la concepción que orientó al Gobierno Nacional a emprender el proceso de paz, firmar el AF e iniciar su implementación. Así se expresa en los documentos de la OCDE y de la banca multilateral sobre las reformas que debe emprender la Colombia del postacuerdo. La llamada cooperación internacional, invocada como fuente principal de recursos para implementarlo, funciona con esa lógica.

El concepto de "paz territorial", mencionado con insistencia durante la negociación de La Habana y en el texto del AF, corresponde a dicho enfoque. De acuerdo con Sergio Jaramillo, Alto Comisionado para la Paz del gobierno de Juan Manuel Santos y uno de sus dos principales negociadores del Acuerdo, el eje del proyecto de paz es la preocupación por el territorio y por los derechos, tanto de las víctimas como de todos sus habitantes. Señala que esto sólo es posible garantizando unas instituciones fuertes y unas normas que rijan la vida social "indispensables para la creación de condiciones de cooperación y convivencia” (Jaramillo, 2013, p. 1). 
Bajo su concepto, el enfoque de derechos debe complementarse con un enfoque territorial, debido a que el conflicto armado ha afectado a unos territorios más que a otros. Se trata entonces de entender la paz como una oportunidad, para que el país progrese de manera equitativa y sostenida, después de resolver el problema del campo y de que se clarifiquen y garanticen los derechos de propiedad sobre la tierra. Y continúa afirmando: "Necesitamos poner en marcha un modelo nuevo e incluyente de fortalecimiento de las instituciones en las regiones" ( $\mathrm{Ibid}, \mathrm{p}$. 5), al tiempo que destaca la importancia de la participación de las comunidades y de su alianza con el Estado. En este mismo sentido se pronuncia la Fundación Ideas para la Paz (FIP), constituida por algunos de los empresarios más importantes del país y de mucha influencia en el proceso de negociación (Guarín, 2016). Sin embargo, es claro que como resultado de la negociación el texto del AF trasciende lo expresado en dicho concepto, tal como se analizará más adelante.

La concepción subyacente de paz territorial plantea serias limitaciones y contradicciones para el cumplimiento del AF y la consolidación de la paz. Es cierto que en el discurso y en la letra se reconoce la diversidad de factores que emergieron o se agudizaron con el conflicto armado: la disputa por la tierra y los territorios, el narcotráfico, el impacto de la minería, el conflicto por el agua y los recursos. Sin embargo, se hace abstracción de las políticas agrarias del Estado que favorecen la concentración de la tierra y la exclusión de la población rural y se convierten en un obstáculo para mejorar las difíciles condiciones de vida y de trabajo de la gran mayoría de los campesinos.

Más contradictoria todavía resulta la relación de los campesinos con los grandes empresarios, tal como se plantea en el AF, pues se expresa que el desarrollo integral del campo depende de un "adecuado balance entre la agricultura familiar y la agricultura comercial a gran escala” (AF, 2016, p. 12), un balance imposible, en términos de las relaciones de poder vigentes. Pues si bien es cierto que el objetivo inmediato del Acuerdo era ponerle fin al conflicto armado, su cumplimiento cabal por parte del gobierno requiere trascender los límites estrechos y el sesgo en contra de los campesinos, propios de la visión neoliberal-neoinstitucionalista.

La noción de paz territorial, centrada en la idea de que el fin del conflicto armado debe llevar al crecimiento económico y al incremento de la inversión extranjera, es cuestionada desde diversas perspectivas. Para García (2016), la paz territorial propuesta termina vinculando la finalización del conflicto armado con la libertad de empresa y la seguridad jurídica, lo que la convierte en un mecanismo para profundizar el modelo de desarrollo y no para cuestionar las estructuras que determinan relaciones so- 
ciales excluyentes. Mientras que Salcedo (2015) señala que el mantenimiento de una paz duradera requiere, entre otros puntos, revisar el modelo de desarrollo nacional y sus efectos sobre la inequidad del país, lo mismo que el ordenamiento territorial vigente. Debe contarse con alternativas a los cultivos de coca, para garantizar que se den opciones reales de sustitución que les permitan a los campesinos vivir dignamente. Por su parte, Ramos (2016) defiende la noción de una paz transformadora y participativa, aunque si bien reconoce que concebir la paz desde esa corriente liberal fue lo que permitió la salida política al conflicto armado, precisamente porque no se puso en discusión el modelo de desarrollo. Desde una perspectiva similar, Bautista (2017) propone trascender la lógica de la focalización neoliberal, generar un nuevo ordenamiento territorial, incentivar la participación social y comunitaria, y asumir la construcción social y la transformación del territorio en toda su diversidad.

Otro punto de discusión importante tiene que ver con el enfoque territorial. Umańa (2017) considera que ponerlo en práctica, tal como lo contempla el AF, plantea enormes dificultades, debido a que las políticas públicas están estructuradas con base en una división presupuestal por sectores, que desconoce el contexto territorial y a su vez limita la posibilidad de que este enfoque se concrete en programas y proyectos específicos de desarrollo. Frente a este mismo punto, Schejtman y Ramírez (2004, p. 9) cuestionan la visión que prevalece sobre el enfoque territorial y señalan que hay conflictos, tales como los motivados por la minería y los recursos naturales, que por su magnitud requieren de un enfoque más radical, socioterritorial "que contemple el conflicto como elemento constitutivo de las relaciones sociales que construyen un territorio determinado".

Así pues, existen problemas de fondo que derivan de políticas económicas nacionales vigentes durante las últimas tres décadas. Como en otras latitudes, en Colombia el proceso de descentralización, presentado como la panacea para el desarrollo regional y la democratización política, tuvo efectos contrarios en la medida en que profundizó las desigualdades entre las regiones e incrementó la dependencia de las entidades territoriales frente al Estado central. Sucesivas reformas llevaron a reducir el porcentaje de las transferencias financieras a las regiones, incluidas en la Constitución de 1991, al tiempo que se incrementaron las responsabilidades de estas entidades en la atención de asuntos esenciales como salud, educación y saneamiento básico.

La gran mayoría de los municipios, pero en especial los más golpeados por el conflicto armado, dependen en una alta proporción del monto de estas transferencias para atender sus necesidades básicas. La crisis que atraviesa el 
Sistema General de Participaciones (sGP), que reglamentó las transferencias constitucionales mediante la Ley 1176 de 2007, pone en evidencia esta situación. En el plano político, destaca el peso del clientelismo y de la corrupción regionales avaladas desde el nivel central por los partidos que controlan el Estado. Ello concentra cada vez más las decisiones en las élites nacionales y regionales, minimizando el derecho de las comunidades a decidir sobre los asuntos que les atañen, en medio de una disputa feroz por el poder local y el control territorial que a continuación se examina.

\section{DISPUTA POR EL CONTROL TERRITORIAL Y POLARIZACIÓN POLÍTICA EN TORNO AL AF}

\section{El conflicto armado y la lucha por el control territorial}

El conflicto armado colombiano se centró en zonas rurales alejadas de las principales ciudades, pero provistas de una estratégica localización geográfica. De acuerdo con el informe del Centro Nacional de Memoria Histórica (CNMH) "la apropiación, el uso y la tenencia de la tierra han sido motores del origen y la perduración del conflicto armado" (2013, p. 21). Partiendo del análisis de sus múltiples dimensiones y con la documentación de procesos emblemáticos en todo el territorio nacional y escuchando a las víctimas, este informe fundamenta la estrecha conexión que existe entre la disputa por el control territorial y el conflicto armado. Así, la pelea histórica por la tierra del periodo de "La Violencia" se recrudeció en las últimas décadas por la irrupción del narcotráfico y otros negocios ilegales.

El impacto que ha tenido el conflicto armado colombiano desde la década de 1960 en término de víctimas humanas, es impresionante. El informe señala que hubo 218094 muertos, de los cuales 82\% corresponde a población civil. En marzo de 2013, en el Registro Único de Víctimas (RUV), había 25007 desaparecidos y 27023 personas secuestradas entre 1970 y 2010, entre otros delitos (CNMH, 2013, p. 33). En un informe posterior, se señala que hasta el 2014 había 6459501 personas desplazadas. De ellas, más de la mitad son mujeres y 2279576 menores de edad, entre ellos más del 50\% tienen menos de 12 años (CNMH, 2015, p. 16).

Aparte del enorme costo en vidas humanas, así como de la destrucción material, el efecto más grave del conflicto armado colombiano fue el incremento considerable en la concentración de la propiedad rural. Según fuentes oficiales, más de 8.3 millones de hectáreas, correspondientes a 358937 predios, 
fueron despojados o abandonados a la fuerza (CNMH, 2013, p. 76). El informe indica que fue entre 1996 y 2005 cuando "la guerra alcanzó su máxima expresión, extensión y niveles de victimización. El conflicto armado se transformó en una disputa a sangre y fuego por las tierras, el territorio y el poder local", precisamente cuando se dio la mayor expansión del paramilitarismo y se presentaron las grandes masacres (CNMH, 2013, p. 156).

Este periodo se caracteriza por el despojo como una práctica violenta, ejercido por los paramilitares y en menor medida la guerrilla, valiéndose de "diferentes mecanismos de coacción y violencia como pillaje, extorsiones, masacres, asesinatos selectivos, desapariciones forzadas, amenazas y violencia sexual". Así, obligaron a los campesinos a abandonar sus tierras, ocupadas de inmediato por los despojadores, quienes las pusieron al servicio de sus actividades criminales (CNMH, 2013, p. 76). Colombia se convirtió entonces en el segundo país del mundo en cuanto al desplazamiento forzado interno, después de Sudán. Sin duda, este periodo de intensificación del conflicto armado trajo la mayor concentración de la tierra. Además del control territorial, la lucha se extendió también a los dominios político, social y cultural (CNMH, 2013).

La tendencia a la concentración de la propiedad rural es corroborada por otros estudios. Por ejemplo, IGAC-CEDE (2012) registra que, aunque hacia finales de la década de los ochenta se fortaleció la mediana propiedad rural, este proceso se revirtió a partir de los años noventa, cuando disminuyó la pequeña y mediana propiedad y dio paso al incremento de la gran propiedad. Con base en la información proporcionada por el Tercer Censo Nacional Agropecuario, adelantado por el Estado en 2014, tras 45 años sin que se hiciera ninguna medición de este tipo, OXFAM desarrolla un estudio comparativo sobre la concentración de la tierra en América Latina donde muestra cómo la desigualdad rural se incrementó en forma extrema en Colombia: el 1\% de los propietarios ocupa el $81 \%$ de la tierra, mientras el 99\% sólo dispone del $19 \%$, lo que lo convierte en el país de mayor concentración de la propiedad rural de la región (OXFAM, 2016).

Debe señalarse también que la apertura económica y la eliminación de las instituciones agrarias durante las tres últimas décadas tuvieron un efecto perverso en cuanto a la intensificación del conflicto armado. El informe del CNMH (2013) muestra cómo estas reformas neoliberales propiciaron la extensión del narcotráfico, la apropiación masiva de tierras por los señores de la droga y de la guerra; el incremento de la ganadería extensiva, y el debilitamiento de la economía campesina. 
Es bajo este contexto que los actores del conflicto armado pudieron adelantar la reconfiguración económica del territorio, casi siempre con la complicidad de agentes del Estado a nivel nacional y regional. Los paramilitares y la guerrilla promovieron y se beneficiaron del latifundio ganadero, la agroindustria, la minería y los megaproyectos. Uno de los casos más representativos fue la alta concentración geográfica del cultivo de palma africana sobre el corredor estratégico y la zona de retaguardia de las Autodefensas Unidas de Colombia (AUC), origen del paramilitarismo (CNMH, 2013, p. 177). Consideración similar puede hacerse de la industria bananera en Urabá, en la misma región del noroeste del país, en la frontera con Panamá.

\section{La polarización política y el control del Estado por parte de los enemigos del AF}

Durante los últimos años, las contradicciones políticas de fondo del país giraron en torno al conflicto armado, su naturaleza y su posible superación. Mientras que el proceso de paz fue defendido por el espectro democrático del país, en sentido amplio, sus opositores han sido diversos sectores, algunos de los cuales representan al poder paramilitar y mafioso, ligado al control territorial y al poder político regional y nacional. ${ }^{6}$

Al respecto, debe señalarse que el expresidente Álvaro Uribe Vélez niega incluso la existencia misma del conflicto armado y sus raíces históricas en Colombia e insiste en que este no es más que una expresión de la cruzada antiterrorista global que impulsó el expresidente George Bush en Estados Unidos durante la primera década del presente siglo. Por lo tanto, sigue insistiendo en la confrontación militar que marcó sus dos periodos de gobierno. A partir de esta concepción, sus seguidores se han opuesto de manera sistemática y violenta a la paz, a la restitución de tierras y a la reparación de las víctimas del conflicto armado.

La base social de esta corriente regresiva son hacendados, empresarios del sector rural, políticos nacionales y regionales, así como también importantes mandos del Ejército Nacional. Es un sector caracterizado como emergente por

6 Álvaro Uribe Vélez desempeñó un papel decisivo en el fortalecimiento del paramilitarismo en Colombia, primero como gobernador del departamento de Antioquia (1995-1997), cuando le dio impulso a las cooperativas Convivir, que fueron su germen, y después como presidente de la República (2002-2010), cuando puso el Estado y sus instituciones al servicio de dicho proyecto criminal. 
su irrupción tardía (década de los ochenta) en la política nacional, desde los negocios ilícitos. Se nutre de la supervivencia de una cultura rezagada de corte feudal que se apoya en creencias religiosas con sesgo marcadamente conservador. Por supuesto que el rechazo a los desafueros cometidos por la guerrilla en las últimas décadas, en especial la extorsión y el secuestro, y la manipulación mediática de estos hechos, han conferido a dicha corriente el apoyo de importantes sectores de la población en el campo y la ciudad, en especial durante los procesos electorales.

En contraste con la figura de Uribe, el expresidente Juan Manuel Santos representa a la élite que detenta el poder político y económico en el país durante más de un siglo, responsable directa de las difíciles condiciones sociales y del rezago de amplias zonas del territorio nacional. Este sector, cuyo sometimiento a las directrices provenientes de Estados Unidos ha sido incondicional, tiene como base económica y social a los grandes empresarios, principalmente urbanos, ligados al capital extranjero. Su ruptura con Uribe en cuanto al proceso de paz tiene que ver con la necesidad percibida por ellos de superar el conflicto armado, con el objeto de mejorar las condiciones para los negocios. Sin embargo, pese a esta contradicción, ambos expresidentes se identifican con el modelo de desarrollo excluyente prevaleciente. De hecho, Santos fue un alto funcionario del gobierno de Uribe. Por supuesto, esta caracterización no pretende minimizar el importante papel del primero en la concreción del AF con las FARC.

Por último, al examinar la polarización frente al proceso de paz, es importante también referirse el cambiante papel desempeñado por Estados Unidos en los últimos años. Durante el proceso de negociación (2012-2016) y de renegociación (octubre-noviembre de 2016), cuando se perdió el plebiscito aprobatorio del Acuerdo, el gobierno de Barack Obama, representado entonces por su enviado especial Bernard Aronson, jugó un papel importante a favor de éste. Sin embargo, la llegada de Donald Trump modificó de manera sustancial dicha posición.

Durante este periodo, sus altos funcionarios decidieron desconocerlo y entorpecer su implementación. El intento de sabotear la Justicia Especial para la Paz (JEP), la presión para extraditar a los excombatientes, así como la cancelación de la visa a miembros del Poder Legislativo y Judicial que incluye a funcionarios que defienden las medidas del AF es constante. Asimismo, bajo la presión de Estados Unidos, el Gobierno Nacional anunció la reactivación de la fumigación aérea con glifosato a los cultivos de uso ilícito, en contra de lo estipulado en el AF y del pronunciamiento de la Corte Constitucional. Esta decisión deja sin efecto la política de sustitución de cultivos desarrollada por el 
gobierno anterior y reduce de manera considerable las alternativas productivas para los campesinos y los excombatientes que se reincorporan a la vida civil en medio de múltiples obstáculos.

\section{LOS COMPROMISOS CENTRALES DE LA RRI Y SUS DIFICULTADES}

\section{El nuevo gobierno y el AF}

El 7 de agosto de 2018 tomó posesión el presidente Iván Duque, del Centro Democrático, partido de Álvaro Uribe, principal opositor al proceso de paz y al AF. De esta forma, dio inicio un periodo todavía de mayor dificultad para su implementación y de restricción significativa de las garantías democráticas y constitucionales en todo el país. Acorde con su posición política, el nuevo gobierno sigue una política tendiente a desvirtuar la esencia misma del AF, sus aspectos centrales y su carácter integral, entorpeciendo su implementación e insiste en que los compromisos derivados del mismo son del gobierno anterior y no del Estado, desconociendo así su carácter obligatorio, ratificado en más de una ocasión por la Corte Constitucional de Colombia y por las Naciones Unidas. En dicha lógica, Duque adopta varias medidas, entre ellas, el cambio del carácter y la función de las instituciones creadas por el gobierno anterior para implementar el Acuerdo y el nombramiento de opositores al mismo para adelantar estas funciones, en especial en lo que se refiere a la RRI. Pero también es grave su intención de borrar la memoria histórica del conflicto y de tratar de reescribirla desde la perspectiva de los victimarios (Plataformas de derechos humanos, 2019).

Sin embargo, en este intento encontró una fuerte oposición en el país y resistencia por parte de un sector importante del Congreso y del Poder Judicial. Algunos de los puntos más controvertidos son sobre todo la RRI, la JEP y las Circunscripciones Transitorias Especiales de Paz, más conocidas como las curules para las víctimas del conflicto armado. El presente análisis se centra sólo en el primer punto.

En toda esta arremetida abierta o encubierta para desvirtuar el AF, el gobierno se ha visto forzado a utilizar un doble discurso debido a la continua supervisión y presión a favor de su implementación por parte de instituciones como las Naciones Unidas y la Corte Penal Internacional (CPI), así como la Unión Europea y los países garantes del Acuerdo. Por ello, en los escenarios internacionales, el presidente y sus ministros invocan la paz. En el discurso 
en el ámbito nacional se le defiende o ataca, según las circunstancias y los personajes, pero en la práctica se ignora el AF o se invoca para tergiversarlo y atacarlo.

Se pretende desconocer su carácter complejo e integral, expresado en la articulación entre sus seis puntos, con lo que se le despoja de su poder transformador. El gobierno busca reducir el AF a proveer las garantías para la reincorporación de los excombatientes, recogida en el punto tres del AF, un proceso que se adelanta bajo la supervisión de las Naciones Unidas. Sus múltiples tropiezos, retrasos e incumplimientos llevan a que un número no determinado de excombatientes engrosen la disidencia. El principal problema es el compromiso de proteger la vida de los excombatientes. Aunque desde el gobierno anterior empezaron los asesinatos, durante el mandato de Duque se han incrementado de manera notoria debido a nuevos factores, entre ellos, la retórica bélica de altos funcionarios del Estado y la indiferencia y/o complicidad de mandos altos y medios del Ejército. El nuevo gobierno cambió a la alta cúpula militar, forzando el retiro de quienes participaron en el proceso de negociación de La Habana.

Además de la eliminación física de excombatientes, reviste especial gravedad el asesinato de personas vinculadas a la restitución de tierras, la sustitución de cultivos, la defensa de los derechos humanos, el medio ambiente y los recursos naturales, en todo el territorio nacional, pero en especial en algunas de las zonas más conflictivas. De acuerdo con un informe presentado por INDEPAZ (2019, p. 10), entre el 24 de noviembre de 2016 y mayo de 2019, fueron asesinados 726 personas, representadas en 591 líderes y lideresas sociales y 135 excombatientes de las FARC. Los reiterados argumentos del Gobierno Nacional según los cuales no existe sistematicidad en los crímenes o que se deben a asuntos personales, así como la campaña de estigmatización abierta de funcionarios del Estado contra ellos han provocado la alerta y el rechazo de instituciones y organismos internacionales que le hacen seguimiento al AF.

En cuanto al recrudecimiento del conflicto, habría que mencionar también la ineficiencia del gobierno anterior para ocupar los territorios que antes tenían las FARC, lo que aleja las perspectivas de paz en algunas regiones como el litoral del Pacífico y el Catatumbo, en la frontera con Venezuela. De acuerdo con informes de la Fundación Paz \& Reconciliación (2017), las zonas abandonadas por la guerrilla desmovilizada son ocupadas por diversos actores armados, incluidos el ELN, bandas criminales, entre ellas, carteles mexicanos, disidencias de las FARC y delincuentes comunes. A esta situación habría que sumar la ruptura por parte del nuevo gobierno de las negociaciones que se 
adelantaban con el ELN. Por supuesto que la actitud de esta organización frente al gobierno anterior y su respuesta a la política del nuevo gobierno han incidido también en la reactivación del conflicto armado.

\section{Los compromisos de la RRI}

Tal como ya se señaló, el AF no contempla cambios de fondo en cuanto al modelo de desarrollo y la tenencia de la tierra. Sin embargo, la RRI plantea una transformación agraria que, si se cumpliera, representaría un avance significativo para consolidar la paz y para mejorar las condiciones de vida de la población rural. Desde la introducción misma de este punto se enuncian metas bastante ambiciosas, como la de lograr la transformación de la realidad rural colombiana "que integre las regiones, erradique la pobreza, promueva la igualdad, asegure el pleno disfrute de los derechos de la ciudadanía y como consecuencia garantice la no repetición del conflicto y la erradicación de la violencia" (AF, 2016, p. 10). Más adelante, en clara referencia al enfoque de género que está presente en todo el AF, se insiste en la necesidad de garantizar el acceso a la tierra de quienes habitan el campo "y en particular las mujeres rurales y la población más vulnerable, regularizando y democratizando la propiedad y promoviendo la desconcentración de la tierra", así como la igualdad de oportunidades entre hombres y mujeres en la zona rural (Ibid, p. 10).

En el principio correspondiente a Bienestar y Buen Vivir, se plantea como objetivo final de la RRI erradicar la pobreza, para lograr en el menor plazo posible "que los campesinos, las campesinas y las comunidades, incluidas las afrodescendientes e indígenas, ejerzan plenamente sus derechos [...] respetando el enfoque territorial, el enfoque de género y la diversidad étnica y cultural de las comunidades" (AF, 2016, p. 12).

La RRI se estructura en tres ejes: el primero, relativo a la democratización del acceso a la tierra, es la dotación y formalización de tierras para los campesinos, en especial para quienes fueron objeto del despojo; el segundo, la construcción de los Proyectos de Desarrollo con Enfoque Territorial (PDET); y el tercero, la provisión de la infraestructura y de los servicios necesarios para impulsar el desarrollo territorial en las subregiones escogidas para dichos proyectos.

Con respecto al primero de estos ejes, el AF estableció las siguientes tareas: 1) creación de un fondo de tierras de distribución gratuita, con 3 millones de hectáreas, cuyo origen será principalmente la recuperación por parte del Estado de tierras ilegalmente adquiridas, en especial los baldíos; 2) forma- 
lización de 7 millones de hectáreas, correspondientes a pequeña y mediana propiedad; 3) creación de una jurisdicción especial agraria, y 4) actualización del catastro rural (AF, 2016. pp. 14-16). Este último punto es especialmente crítico y uno de los que ha provocado mayor rechazo por parte de los enemigos del AF, por cuanto le proporcionaría al Estado la información requerida y la base legal para que los grandes latifundistas del país empezaran a pagar el impuesto predial.

En cumplimiento del AF y con base en las facultades extraordinarias otorgadas al Ejecutivo para legislar en materia de paz, el gobierno de Santos, mediante acto legislativo 01 de 2016, expidió casi 40 decretos ley a finales de mayo de 2017. El decreto 902 reglamentó el procedimiento para el acceso y la formalización de la tierra, así como la constitución del fondo de tierras. Se estableció también, entre otras medidas, la incorporación de proyectos productivos "sostenibles social y ambientalmente", dotados de asistencia técnica para explotar el predio obtenido (Presidencia de la República, 2017b).

En un balance reciente sobre los primeros 30 meses de la implementación del AF, realizado por diversas organizaciones sociales, se señala que este objetivo de democratizar la propiedad de la tierra avanza de manera lenta. El fondo de tierras contaba en julio de 2018 con un inventario de 525 mil hectáreas, pero a partir de esa fecha no se han registrado avances al respecto ni se han desarrollado los programas de vivienda, asistencia técnica, adecuación de tierras, proyectos productivos y otras medidas previstas para los beneficiarios del fondo (CINEP/PPP-CERAC-Secretaría Técnica del Componente Internacional de Verificación 2019, p. 15). Es decir, las reducidas cifras registradas corresponden al gobierno anterior y no al actual. En el mismo documento se señala con preocupación que las perspectivas de la implementación de medidas de acceso a tierras luego de la aprobación del Plan Nacional de Desarrollo (PND), denominado Pacto por Colombia, Pacto por la Equidad (2018-2022), no son positivas, por cuanto este no incluye entre sus propuestas y metas ninguna medida sobre distribución gratuita de tierras a los campesinos y campesinas. Tampoco parece vislumbrarse la creación de la Jurisdicción Agraria (Ibid., p. 17).

En las consideraciones y principios de la RRI se plantea la necesidad de emprender una verdadera transformación estructural del campo y de resolver "la cuestión no resuelta de la propiedad sobre la tierra y particularmente su concentración, la exclusión del campesinado y el atraso de las comunidades rurales, que afecta especialmente a las mujeres, niñas y niños". Asimismo, se invoca el papel del Estado en la provisión de servicios básicos, se destaca la importancia de la economía campesina, familiar y comunitaria en el desarrollo 
agrario y el reconocimiento a las llamadas Zonas de Reserva Campesina (ZRC) y de otras formas de asociatividad campesina (AF, 2016, p. 11). ${ }^{7}$

Otro de los decretos expedidos durante el gobierno de Santos (el 893), reglamentó los PDET y estableció las condiciones para adelantar un programa de inversiones públicas en desarrollo rural, infraestructura y proyectos productivos en 170 municipios, correspondientes a 16 subregiones, los más afectados por el conflicto armado, la ausencia del Estado y el problema de los cultivos de uso ilícito y de otras formas de economía ilegal. En este decreto se estableció también que para cumplir con los objetivos planteados debía elaborarse de manera participativa un Plan de Acción para la Transformación Regional (PATR), que orientara las inversiones públicas en dichas subregiones. Este debía incluir todos los niveles del ordenamiento territorial y acordarse con las autoridades locales y las comunidades (Presidencia de la República, 2017a). Todo este proceso estará bajo la dirección de la Agencia de Renovación del Territorio (ART), de manera articulada con las entidades nacionales, territoriales y las autoridades tradicionales de los territorios de los pueblos, comunidades y grupos étnicos. Según el balance antes mencionado, entre agosto de 2018 y febrero de 2019 se finalizó la planeación en todas las subregiones, pero fue un proceso muy cuestionado por las organizaciones sociales en materia de inclusión del enfoque étnico y de género, así como por la forma en que se desarrolló (CINEP/PPP-CERAC-Secretaría Técnica del Componente Internacional de Verificación, 2019, p. 12).

Una preocupación adicional de las organizaciones sociales y políticas tiene que ver con los componentes de "estabilización" y "paz con legalidad" en los que se basa su Política de Seguridad, introducida en el PND. Se trata entonces de subordinar los compromisos adquiridos con los territorios en el AF al desarrollo de las llamadas Zonas Estratégicas de Intervención Integral (ZEEI), con un enfoque de seguridad centrado en las Fuerzas Militares. Estas zonas se definen como regiones con escasa presencia del Estado o de fronteras con carácter estratégico (Plataformas de derechos humanos, 2019). En la práctica, es el retorno a las oscuras épocas de la llamada "Seguridad democrática" que marcó los dos periodos del presidente Uribe (2002-2010).

7 La Ley 160 de 1994 estableció que la ocupación y aprovechamiento de las tierras baldías de la Nación debe centrarse en su adjudicación a los campesinos de escasos recursos, y establece las llamadas Zonas de Reserva Campesina para fomentar la pequeña propiedad rural. Disponible en

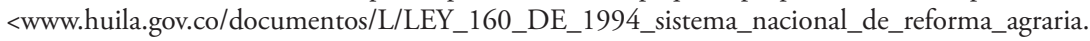
pdf $>$. 


\section{Políticas económicas nacionales}

Las políticas económicas del Gobierno Nacional, que han tenido continuidad durante las últimas tres décadas, van en contravía de la implementación de las medidas contempladas en el AF, sobre todo en lo que se refiere al primer punto. Lo cierto es que durante este periodo la agricultura y la industria se han visto por completo rezagadas, tal como lo muestran las cifras oficiales y de los gremios de la producción. Su situación ha sido todavía más afectada por los tratados de libre comercio con otros países, en especial el que se suscribió con Estados Unidos y que empezó a operar en 2012. Además, desde comienzos del siglo xxI, la explotación minera y de hidrocarburos se constituyó como eje de la economía del país.

Un asunto de especial preocupación es la Ley 1766 de 2016, promovida por la administración de Santos en el contexto de la negociación del AF, misma que reglamentó la creación y el desarrollo de las llamadas Zonas de Interés de Desarrollo Rural, Económico y Social (ZIDres). Según el gobierno anterior, mediante esta ley se pretendía explotar y desarrollar más de 7 millones de hectáreas en la Altillanura, el Urabá chocoano, la Guajira y la Mojana, para promover el desarrollo de proyectos empresariales, mediante una explotación "sostenible" del campo que supondría beneficio a los campesinos. No obstante, tal como lo señalan diversos analistas, es un proyecto insostenible, desde el punto de vista económico y social, lo mismo que en términos ambientales. Lo cierto es que se trata de un instrumento que legalizará la acumulación irregular de predios que antes fueron baldíos, por parte de empresas nacionales y multinacionales extranjeras. Las zonas seleccionadas son algunas de las más golpeadas por el conflicto armado.

La política de ajuste fiscal, consagrada legalmente en Colombia en 2011 mediante la llamada Regla Fiscal y el principio de sostenibilidad fiscal, convertido en principio constitucional, también es nefasta en la perspectiva del cumplimiento del AF, pues se centra en la reducción del gasto público en el país, con el objeto de mantener el equilibrio fiscal, garantizando la sostenibilidad de la deuda pública y la estabilidad macroeconómica.

En este marco, el PND y el Plan Plurianual de Inversiones que lo acompaña, desconocen los compromisos adquiridos por el Estado frente a las perspectivas de una "paz estable y duradera". El PND, que representa la carta de navegación del gobierno, atenta contra el desarrollo nacional, los sectores productivos, los derechos de la población urbana y rural y las perspectivas de consolidar la paz en Colombia. 
Por último, los compromisos adquiridos por el Estado en cuanto a la RRI incluyen la provisión de servicios sociales básicos, entre ellos, la construcción de vías terciarias, distritos de riego, energía, salud, educación, nutrición, vivienda y agua potable (AF, 2016). En el cumplimiento de estos puntos, a las entidades territoriales se les confiere una gran responsabilidad, tanto política como financiera, pero no se contemplan cambios en las políticas vigentes en cuanto a su difícil y conflictiva relación con las autoridades centrales.

\section{CONCLUSIONES}

La culminación exitosa del proceso de paz entre el Gobierno Nacional y las FARC y la firma del AF trajeron la posibilidad de reducir la violencia, civilizar la contienda política, además de plantear alternativas reales para superar el rezago histórico de gran parte del país y construir una sociedad más incluyente, con unas condiciones dignas de vida para la mayoría de sus habitantes. Aunque hay avances significativos, en especial en cuanto a la reducción de la violencia, las perspectivas del AF son bastante inciertas.

El contexto internacional para garantizar su implementación es contradictorio. Existe presión por parte de las Naciones Unidas, la CPI, los países garantes del Acuerdo, y la Unión Europea, para que el gobierno colombiano cumpla con el Acuerdo. Pero al mismo tiempo Estados Unidos exige al Gobierno Nacional adoptar medidas que desconozcan abiertamente lo acordado, tales como la extradición de excombatientes y el reemplazo de la sustitución voluntaria de cultivos de uso ilícito por su erradicación forzada mediante la fumigación aérea con glifosato.

En el plano nacional, los obstáculos que se oponen al establecimiento de una paz estable y duradera son considerables y pueden sintetizarse en dos: el primero, la persistencia de una fuerte oposición al AF, y en especial al punto de RRI, por parte del sector más retardatario de la sociedad colombiana, ligado a la gran hacienda y al poder mafioso y paramilitar. Esta contracorriente es responsable en buena medida del proceso de despojo y concentración de tierras, en el marco del conflicto armado, y es la que controla ahora el Estado.

El segundo obstáculo es la prevalencia de unas políticas excluyentes, derivadas de la globalización neoliberal, que favorecen la concentración de la riqueza y limitan seriamente el cumplimiento del AF. Al tiempo que proclaman su compromiso con la paz de Colombia, las entidades financieras internacionales insisten en imponer políticas económicas que atentan contra la implementación del Acuerdo. La visión limitada de la paz territorial refleja dicha 
concepción. Por ello, su implementación exitosa y el camino hacia la consolidación de la paz suponen trascender este estrecho marco analítico y político.

Por último, el problema de fondo sobre las políticas de desarrollo y la relación entre las decisiones nacionales y las entidades territoriales debe resolverse. Tal como lo demuestra la experiencia histórica de otros países que han tenido que reconstruirse después de un conflicto armado, de una guerra o de cualquier evento catastrófico, la implementación del AF en Colombia requiere del fortalecimiento de la presencia integral del Estado en los territorios más afectados por el conflicto armado. Es prioritario mantener por un largo periodo una fuerte inversión pública y social para resarcir a las comunidades, no sólo de los efectos del conflicto mismo, sino de la escasa inversión pública histórica por parte del Estado. Pero también resulta fundamental democratizar los procesos y propiciar la participación real y decisoria de las comunidades en el proceso de construcción de la sociedad del posconflicto.

\section{BIBLIOGRAFÍA}

Acuerdo final para la terminación del conflicto y la construcción de una paz estable y duradera (AF) (2016), 24 de noviembre, Bogotá. Disponible en <www.mesadeconversaciones.com.co/sites/default/files/24-1480 106030.11-1480106030.2016nuevoacuerdofinal-1480106030.pdf>

Banco Mundial (1997), Informe sobre el Desarrollo Mundial 1997: el Estado en un mundo en transformación, Washington. Disponible en <http:// documentos.bancomundial.org/curated/es/973681468778813985/Resumen-del-informe-sobre-el-desarrollo-mundial-1997-el-Estado-en-unmundo-en-transformaci-243-n>

Bautista, S. C. (2017), "Contribuciones a la fundamentación conceptual de paz territorial”, Revista Ciudad Paz-ando, vol. 10, núm. 1, Bogotá. Disponible en <https://doi.org/10.14483/2422278X.11639>

Centro Nacional de Memoria Histórica (CNMH) (2013), ¡Basta ya! Colombia: memorias de guerra y dignidad, Bogotá. Disponible en <http://www.centrodememoriahistorica.gov.co/micrositios/informeGeneral/estadisticas. html>

(2015), Una nación desplazada: informe nacional del desplazamiento forzado en Colombia, Bogotá, CNMH-UARIV.

CINEP/PPP-CERAC-Secretaría Técnica del Componente Internacional de Verificación (2019), Documento de balance de los primeros 30 meses de la implementación del Acuerdo Final, Bogotá, septiembre. 
Fundación Paz \& Reconciliación (31 de enero de 2017), Informe. ¿En qué están los territorios que dejan las FARC?, Bogotá. Disponible en <http://www. pares.com.co/carrusel/en-que-estan-los-territorios-que-dejan-las-farc/>

García, S. (2016), "Paz territorial: ni territorio ni paz", Revista Nova et Vetera, vol. 2, núm. 18, Bogotá, Universidad del Rosario, agosto. Disponible en <https://www.urosario.edu.co/revista-nova-et-vetera/Inicio/Omnia/ Paz-territorial-ni-territorios,-ni-paz/>

Guarín, S. (2016), "La paz territorial y sus dilemas: la participación ciudadana”, Razón Pública, Bogotá, enero. Consultado el 17 de enero de 2017 en $<$ https://www.razonpublica.com/index.php/conflicto-drogas-y-paztemas-30/9174-la-paz-territorial-y-sus-dilemas-la-participaci\%C3\%B3nciudadana.html>

Instituto Geográfico Agustín Codazzi (IGAC) y Centro de Estudios de Desarrollo Económico (CEDE) de la Universidad de los Andes (2012), Atlas de la distribución de la propiedad rural en Colombia, Bogotá, Imprenta Nacional de Colombia.

IndePaz-Marcha Patriótica (mayo de 2019), “Todos los nombres, todos los rostros", Separata de actualización, Bogotá. Disponible en <http://www. indepaz.org.co/wp-content/uploads/2019/05/SEPARATA-DE-ACTUA LIZACIO\%CC\%81N-mayo-Informe-Todas-las-voces-todos-los-rostros.23-mayo-de-2019-ok.pdf>

Jaramillo, S. (2013), La paz territorial, Oficina del Alto Comisionado para la Paz, Bogotá. Consultado el 17 de enero de 2017 en <https://interaktivedemokratie.org/files/downloads/La-Paz-Territorial.pdf>

Kalmanovitz, S. (2003), "El neoinstitucionalismo como escuela", Revista Economía Institucional, vol. 5, núm. 9, Universidad Externado de Colombia, julio-diciembre.

Kuczynski, P. P. y Williamson, J. (eds.) (2003), After the Washington Consensus: restoring growth and reform in Latin America, Washington, Institute for International Economics.

López, A. (2005), "Los fundamentos de la Nueva Gestión Pública. Lógica privada y poder tecnocrático en el Estado mínimo", en Th. Rey y López (eds.), Entre tecnócratas globalizados y politicos clientelistas. Derrotero del ajuste neoliberal en el Estado argentino, Buenos Aires, Prometeo.

Moore, B. (1991[1973]), Los orígenes sociales de la dictadura y de la democracia, Barcelona, Ediciones Península.

North, D. (1993), Instituciones, cambio institucional y desempeño económico, México, Fondo de Cultura Económica. 
oxfam (2016), Radiografía de la desigualdad. Lo que nos dice el último censo agropecuario sobre la distribución de la tierra en Colombia, oxfaM Internacional, Gran Bretaña. Disponible en <https://www.oxfam.org/es/informes/radiografia-de-la-desigualdad>

(2019), ¿Bienestar público o beneficio privado?, oxfam Internacional, Gran Bretaña. Disponible en <https://www.oxfam.org/es/informes/bienestar-publico-o-beneficio-privado>

Plataformas de derechos humanos (2019), El aprendiz del embrujo. Finge la paz, reinventa la guerra y privatiza lo público. Balance del primer año de gobierno de Iván Duque, Bogotá, Ediciones Antropos.

Portes, A. (2006), "Instituciones y desarrollo. Una revisión conceptual", Cuadernos de Economía, vol. 25, núm. 45, Bogotá, Universidad Nacional de Colombia, diciembre. Disponible en <http://www.scielo.org.co/scielo. php?script=sci_arttext\&pid=S0121-47722006000200002>

Presidencia de la República (2017a), Decreto Ley 893 del 27 de mayo de 2017, Bogotá, Colombia. Recuperado de <http://www.funcionpublica.gov.co/ eva/gestornormativo/norma.php?i=81856>

(2017b), Decreto Ley 902, 29 de mayo de 2017, Bogotá, Colombia. Recuperado de <https:/www.unidadvictimas.gov.co/sites/default/fi les/documentosbiblioteca/decreto902del29demayode2017.pdf>

Ramos, E. (2016), "El proceso de construcción de paz colombiano más allá de la negociación: una propuesta desde la paz transformadora y participativa”, El Ágora USB, vol. 16, núm. 2, Medellín-Colombia. Disponible en $<$ http://www.scielo.org.co/pdf/agor/v16n2/v16n2a09.pdf>

Salcedo, L. (2015), Propuestas de paz territorial desde los movimientos sociales. Multiculturalismo, ordenamiento territorial y ejemplos de paz territorial, Fescol, Documentos análisis, 10/2015, Bogotá, Colombia.

Schejtman, A. y Ramírez, E. (2004), Desarrollo territorial rural, aspectos destacados de experiencias en proceso en América Latina, edición Fondo Mink'a de Chorlavi, $1^{a}$ edición, lugar $\mathrm{n} / \mathrm{d}$. Disponible en <https://core.ac.uk/ download/pdf/48026178.pdf>

Umaña, M. (2017), “¿Qué ha pasado con el enfoque territorial en Colombia?”, La Silla Llena, Bogotá, enero. Disponible en <https://lasillavacia. $\mathrm{com} /$ silla-llena/red-rural/historia/que-ha-pasado-con-el-enfoque-territorial-en-colombia-59317>

Vilas, C. (2000). “¿Más allá del Consenso de Washington? Un enfoque desde la política de algunas propuestas del Banco Mundial”, América Latina Hoy, núm. 26, España, Universidad de Salamanca, diciembre. Disponible en $<$ www.redalyc.org/articulo.oa?id=30802604> 
